\title{
Fabrication and Characterization Of Copper Doped Polymer/Bioactive Glass Composite Scaffolds
}

\author{
Nuray Yerli, Melek Erol Taygun, Yakup Yürektürk, Sadriye Küçükbayrak \\ Chemical and Metallurgical Engineering Faculty, Istanbul Technical University, Maslak 34469, Istanbul, Turkey \\ yerli@itu.edu.tr; erolm@itu.edu.tr; yurekturk@itu.edu.tr; sadriye@itu.edu.tr
}

\section{Extended Abstract}

Tissue damage and degenerative diseases such as large bone defects are among the most human health issues which lead to organ failure and death all over the world [1-3]. Bone tissue engineering emerges a promising approach to repair bone defects, especially large bone defects resulting from trauma, infections, tumors or genetic malformations [2-4]. The development of scaffolds and their processing into structures are becoming increasingly important in bone tissue engineering applications. Three-dimensional (3D) scaffolds should show a highly porous, open structure to allow a proper vascularisation of the implant, as well as the flow of nutrients and waste products through the scaffold. Major issues of bone tissue engineering scaffolds include the use of appropriate matrix materials for scaffolds, control of porosity and pore characteristics of scaffolds, mechanical strength of scaffolds as well as scaffold degradation properties [5]. Ideal bioactive porous scaffolds, which are used in bone tissue engineering applications, should meet multifunctional properties such as angiogenesis, osteostimulation and antibacterial properties for the treatment of large bone defects [2]. Among these properties, angiogenesis plays an important role for the formation and repair of new tissue because blood vessels provide for newly formed tissues to receive nutrients and oxygen. The stimulation of angiogenesis by the delivery of inorganic ions from biomaterial scaffolds provide to reduce cost of treatments and also prevent biological side effects when compared to the use of growth factors and so it has been attracting considerable interest in recent years [6]. The focus of this study is on advanced bioactive scaffolds enabling internal growth of tissue and controlled delivery of therapeutic ion. To be able to achieve this goal, in the first stage bioactive glass (composition in weight; $45 \% \mathrm{SiO}_{2}, 24.5 \% \mathrm{Na}_{2} \mathrm{O}, 6 \% \mathrm{P}_{2} \mathrm{O}_{5}, 24.5 \% \mathrm{CaO}, 2 \% \mathrm{CuO}$ ) were developed which have antibacterial and angiogenic properties. After the production of bioactive glass, bioactive glass/polymer 3D composite multifunctional scaffolds were fabricated by using foam replication technique. Then, they were coated with alginate at different percentages (in weight; $1,2,3 \%$ ) to improve the properties of them. The obtained scaffolds were immersed in simulated body fluid (SBF) at different time points $(1,7,14$ and 28 day) to investigate the bioactivity and biodegradability behavior of the samples. Physical and micro structural properties of the obtained scaffolds were determined by using different characterization techniques. Scanning electron microscopy investigations showed that scaffolds have highly porous structure with a good pore interconnectivity. After immersion in SBF for 28 days, the hydroxyapatite layer formation was observed significantly on the surface of the scaffolds. X-Ray Diffraction (XRD) and Fourier Transform Infrared Spectroscopy (FTIR) analysis also verified the bioactivity of the obtained scaffolds. Characteristic chemical bonds which belongs to hydroxyapatite were obtained with FTIR and degree of hydroxyapatite was detected from the result of XRD analysis. Physical and mechanical properties of the composite scaffolds were studied and compared with each other. Inductively Coupled Plasma (ICP) analysis was also applied to investigate the copper release behavior of the scaffolds in SBF and the results indicated that the alginate coated scaffolds allowed controlled release of copper ions but in low amounts compared to uncoated ones. The overall results showed that three dimensional composite scaffolds could be promising candidates for bone tissue engineering applications.

\section{References}

[1] J. K. Leach, D. Kaigler, Z. Wang, P. H. Krebsbach, and D. J. Mooney, "Coating of VEGF-releasing scaffolds with bioactive glass for angiogenesis and bone regeneration," Biomaterials, vol. 27, pp. 3249-3255, 2006.

[2] C. Wu, Y. Zhou, M. Xu, P. Han, L. Chen, J. Chang, and Y. Xiao, "Copper-containing mesoporous bioactive glass scaffolds with multifunctional properties of angiogenesis capacity, osteostimulation and antibacterial activity," Biomaterials, vol. 34, no. 2, pp. 422-433, 2013. 
[3] S. Zhao, H. Wang, Y. Zhang, W. Huang, M. N. Rahaman, Z. Liu, D. Wang, and C. Zhang, "Copper-doped borosilicate bioactive glass scaffolds with improved angiogenic and osteogenic capacity for repairing osseous defects," Acta Biomaterialia, vol. 14, pp. 185-196, 2015.

[4] W. Li, P. Nooeaid, J. A. Roether, D. W. Schubert, and A. R. Boccaccini, "Preparation and characterization of vancomycin releasing PHBV coated 45S5 Bioglass ${ }^{\circledR}$-based glass-ceramic scaffolds for bone tissue engineering," Journal of the European Ceramic Society, vol. 34, no. 2, pp. 505-514, 2014.

[5] D. W. Hutmacher, "Scaffolds in tissue engineering bone and cartilage," Biomaterials, vol. 21, no. 24, pp. 2529-43, 2000.

[6] H. Wang, S. Zhao, J. Zhou, Y. Shen, W. Huang, C. Zhang, M. N. Rahaman, and D. Wang, "Evaluation of borate bioactive glass scaffolds as a controlled delivery system for copper ions in stimulating osteogenesis and angiogenesis in bone healing," Journal of Materials Chemistry B, vol. 2, no. 48, pp. 8547-8557, 2014. 